\title{
Dietary Approaches and Supplements in the Prevention of Cognitive Decline and Alzheimer's Disease
}

\author{
Ligia J. Dominguez* and Mario Barbagallo
}

Geriatric Unit, Department of Internal Medicine and Geriatrics, University of Palermo, Palermo, Italy

\begin{abstract}
Age-associated cognitive decline and dementia are conditions in which there is deterioration in memory, thinking, and behavior, with profound effects on the ability to perform everyday activities and well-being. Even if dementia mainly affects older persons, it is not a normal part of aging. Alzheimer's disease accounts for $60-75 \%$ of dementia cases. The number of persons affected will increase in the next decades in parallel with aging of the world population. Hence, unless some approach is found to reduce age-related deterioration of cognitive functions, health care costs will continue to rise exponentially. There is a wealth of epidemiological evidence supporting a relationship between diet and Alzheimer's disease, and suggesting that the risk of cognitive decline may be reduced by dietary interventions. It has been proposed that adopting a healthy diet and lifestyle that improves cardiovascular function may help delaying the onset of Alzheimer's disease due to its potential association with vascular disease. Several nutrients, dietary components, supplements and dietary patterns have been reported in relation to their association with cognition and with the development of cognitive decline and Alzheimer's disease. The possible effect of diet on the prevention ogical treatment for dementia. The aim of this review is to evaluate the evidence for the effects of some dietary components, supplements, and dietary patterns as neuroprotective, with potential to delay cognitive decline and the onset of dementia.
\end{abstract}

Keywords: Nutrition, Cognitive decline, Alzheimer, Aging, Diet, Oxidative stress, Inflammation, Supplement.

\section{INTRODUCTION}

The cognitive decline that accompanies aging, as well as its extreme manifestation, dementia, are complex conditions with still not well defined causality. The number of persons affected will increase exponentially in the coming decades $[1,2]$ in parallel with aging of the world population [3], with remarkable finance and human burden, being dementia one of the greatest causes of disability [2]. Worldwide, there are an estimated 47 million persons currently affected by dementia, and each year there are about 8 million newly diagnosed cases. Most of them, 60-75\%, have Alzheimer's disease (AD), with other major conditions including vascular dementia and Lewy body dementia $[1,2]$. These numbers imply an extraordinary burden on health care systems, families, caregivers and the individuals themselves.

Despite a large number of research on dementia and other neurodegenerative diseases, the availability of effective interventions to significantly improve cognitive function is still some way off [4]. The hope for a cure for these debilitating diseases seems to represent a laudable mission, an admirable scientific achievement, but incredibly challenging, and if realized, is not likely to occur in the near future.

Nutrition and diet are key factors in the efficient clinical care of persons with cognitive decline of various grades, particularly in those experiencing dementia and AD [5]. Furthermore, the impact of diet and nutrition on cognitive function, and on the development of age-related cognitive decline is becoming a growing field, insofar as more data point to maximize the possible modifiable determinants of these conditions $[6,7]$. Understanding the complex interactions among diverse dietary components, supplements, and dietary patterns with neurocognitive functions may embody opportunities to improve the knowledge of cognitive decline, dementia, and $\mathrm{AD}$, and to influence outcomes.

*Adress correspondence to this author at the Geriatric Unit, Dept. of Internal Medicine and Geriatrics, University of Palermo, Palermo, Italy, Viale F. Scaduto 6/c, 90144 Palermo, Italy; Tel: 0039-91-6552885;

Fax: 0039-91-6552952; E-mail: ligia.dominguez@unipa.it
Diverse vitamins, minerals, and micronutrients have important potential antioxidant/anti-inflammatory and free-radical scavenging properties that may protect against brain oxidative damage, neuroinflammation, and consequent cognitive decline [8]. Most fatty acids in neuronal membranes are essential and must be obtained from the diet [9]. Fish oil, omega-3 fatty acids, eicosapentaenoic acid (EPA), and docosahexaenoic acid (DHA) may possess antioxidant, anti-excitotoxic, and anti-inflammatory effects in brain tissue. DHA is one of the major building structures of membrane phospholipids and it is necessary for normal neuronal function. It has been involved in neurotrophic, anti-apoptotic, and anti-inflammatory signaling [10]. Similar arguments may support the biological plausibility of other specific supplements, but review of the clinical literature suggests that a plausible mechanism of action does not necessarily translate into significant benefits in normal aging adults or those with cognitive decline or dementia. Several dietary patterns have been studied in relation to their association with cognitive functions. Indeed, the evidence for benefit may derive from synergistic interactions of different components put together in a food pattern [11].

In this review, we present the possible mediators and evidence for the effects of some dietary components, supplements, and dietary patterns as neuroprotective, with potential to delay cognitive decline and the onset of dementia.

\subsection{Possible Mediators and Associated Factors of the Effects of Diet and Supplements on Cognitive Decline and AD}

\subsubsection{Oxidative Stress}

Aging and age-related degenerative diseases, including neurodegeneration, are characterized by a pro-oxidant, proinflammatory state, which may contribute to their physiopathology, because of the harmful damage of free radicals on cellular components. The brain is particularly susceptible to undergo oxidative damage. Cerebral metabolism requires high levels of energy, and it is closely dependent on aerobic conditions; it is also very rich in polyunsaturated fatty acids (PUFA), easily oxidizable, and in transition metals, likely to facilitate the formation of oxygen free radi- 
cals. Additionally, the brain has a low content of antioxidant systems compared to other tissues and organs in the body. Thus, the alteration of oxidative metabolism associated with old age might render the brain tissue prone to damage caused by the accumulation of neurotoxic peptides such as amyloid-beta [12]. Studies on postmortem brain tissue obtained from patients with $\mathrm{AD}$ have shown modifications of several oxidative damage markers, such as increased lipid peroxidation, protein oxidative damage, glycoloxidation, and a reduction of antioxidant enzyme systems [13].

\subsubsection{Chronic Systemic Inflammation and Neuroinflammation}

There is as well growing evidence suggesting that $\mathrm{AD}$ origins are associated with prominent neuroinflammation. Misfolded and aggregated proteins (e.g., amyloid) bind to microglia toll-like receptors (TLRs) and CD4, generating an innate immune response with release of diverse inflammatory mediators. Systemic chronic lowgrade inflammation associated with obesity, aging and chronic diseases, possibly alter immunological responses in the brain and further enhance damage progression [14]. Even if microglia surrounding amyloid plaques and tangles were described in the original publication by Alois Alzheimer, only recently the role of neuroinflammation in neurodegenerative disorders has been documented and explored. Neuroinflammation is key to protect central nervous system; however, when uncontrolled and persistent, it eventually becomes destructive by the continuous release of reactive oxygen intermediates, cytokines, nitric oxide, proteolytic enzymes, complementary factors, or excitatory amino acids [15]. Neuroinflammation itself may trigger accrual of amyloid-beta by increasing amyloid precursor protein (APP) levels. This has led to the proposed cascade hypothesis of $\mathrm{AD}$, which states that amyloid-beta accumulation induces neuroinflammation, which in turn generates more amyloid-beta, resulting in a vicious cycle and perpetuating damage [16]. Increased neuroinflammation has been reported in both mild cognitive impairment (MCI) and AD patients when compared with healthy controls using positron emission tomography and imaging with radioligand C-11-DAA1106 [17].

The innate immune response is classically characterized by proinflammatory activation of macrophages with subsequent production of specific cytokines, chemokines, and reactive oxygen species (M1); followed by resolution and alternative activation, in which macrophages undertake an anti-inflammatory phenotype (M2) involved in wound repair and debris clearance. Even if there are still heterogeneous results, several investigators start to recognize the importance of microglia M1/M2 dynamics in diseases characterized by chronic neuroinflammation. It is suggested that amyloid-betainduced inflammatory environment in association with age-related effects on microglia, lead to a condition where M1 cells predominate and microglia lose the ability to switch phenotypes and mitigate damage [15]. Concerning nitric oxide (NO), its positive role as promoter of optimal cerebral blood flow at physiological concentrations contrasts with the harmful effect of excessive NO production evoked by inflammatory signals, which have been identified as major players in the pathogenesis of neurodegenerative diseases. Disproportionate synthesis of NO under neuroinflammation leads to the release of reactive nitrogen species and neuronal death [18].

\subsubsection{Prothrombotic State}

Alzheimer's disease is also characterized by vascular pathology (cerebrovascular dysfunction, decreased cerebral blood flow, and blood brain barrier [BBB] disruption, among others) and a prothrombotic state (increased clot formation, decreased fibrinolysis, and activated platelets). Fibrinogen accumulates together with amyloid-beta and their binding promotes fibrinogen aggregation, amyloid-beta fibrillization, and formation of fibrin clots resistant to degradation. Decreasing fibrinogen not only reduces cerebral amyloid angiopathy and BBB altered permeability, but it also diminishes microglia activation and improves cognitive performance in AD mouse models [19]. In patients with AD, a recent study re- ported higher platelet activating factor acetylhydrolase activity and higher oxidized-LDL levels when compared with control subjects [20].

\subsubsection{Obesity, Metabolic Syndrome, and Insulin Resistance}

Compelling evidence indicates that risk factors for vascular atherosclerosis and for type 2 diabetes (T2D), either combined or in isolation, are also risk factors for the development of cognitive decline and $\mathrm{AD}$ [21]. "Metabolic syndrome" is the name given to clustering of risk factors (i.e., central obesity, hyperglycemia, hypertension, atherogenic dyslipidemia, and a prothrombotic state), which is directly related to the accumulation of visceral adiposity in midlife linked to overeating and sedentary lifestyle with deleterious consequences in late-life, conceived by Morley as the "couch potato" syndrome ]22]. The prevalence of MS is increasing [23], in parallel with the obesity epidemic [24]. Industrialization has facilitated the extensive availability of lots of inexpensive calorie-rich food together with a sedentary lifestyle, which paradoxically contributed to the increased life expectancy in the last century. Excessive nutrition has led to chronic non-communicable diseases comprising obesity, T2D, and cardiovascular disease (CVD) [24], which develop easily but are very difficult to treat. The health consequences of over-nutrition are overwhelming and may become unsustainable. In addition, associations between obesity and impaired cognitive function, as well as greater risk of developing $\mathrm{AD}$ and other dementias, have more recently been recognized. Above and beyond the usual age-related cognitive decline, a growing body of evidence shows that both obesity and metabolic disorders in midlife are associated with poorer cognitive performance, cognitive decline, and dementia in old age. A recent systematic review examined the results of twenty eight longitudinal studies conducted between 2003 and 2013 in three continents with follow-up from 5 to 40 years. Most of the studies demonstrated and increased risk of late-onset dementia in midlife overweight and obese participants (up to 2.44 fold risk, with only three studies reporting no increased risk), providing a strong evidence for the association [25].

Even if the mechanism to explain this increase is still elusive, several possible mediators have been proposed. First, the obesity and overweight-related vascular comorbidities, such as hypertension, atherogenic dyslipidemia, or diabetes, are also risk factors for dementia [21]. However, most of multivariable analysis in the studies included these variables as potential confounder. Second, elevated levels of plasma amyloid proteins have been found in obese persons [26], and the Framingham Offspring Cohort Study reported increased rates of hippocampal brain atrophy associated with memory and executive function decline with midlife obesity. In addition, a longitudinal study reported that being overweight or obese in midlife was associated with lower BBB integrity almost twenty five years later, possibly because of the chemical effects of a high-fat, high-sugar diet [27]. In rats, Western diet consumption produces increased permeability to a peripheral fluorescent tracer in the hippocampus consequent to the BBB dysfunction [28].

Third, a plausible mechanism intensively investigated in recent years is the accumulation and activation of macrophages in adipose tissue, which may trigger systemic and neuroinflammation. Adipose tissue can have immune cells and secrete pro-inflammatory cytokines [e.g., tumor necrosis factor (TNF), interleukin (IL)-1b, IL-6], which sustain low-grade chronic inflammation [29]. Obesity has been as well associated with a switch from M2 macrophages to the proinflammatory M1 phenotype [30]. A recent meta-analysis found that increased plasma levels of C-reactive protein and IL-6 are associated with an increased risk of dementia [31]. Dietary fats, in particular saturated fatty acids (SFA), induce inflammatory responses on microglia, leading to local cytokine production, involving often hypothalamic nuclear factor kappa B (NF-kB) activation, which may lead to apoptosis of key neurons involved in body weight control, central regulation of energy balance, glucose homeostasis, and blood pressure $[32,33]$. While the obesity-induced 
activation of microglia in the hypothalamus is well-documented in animal models [34], there is also evidence of microglia activation in cognitive-related brains regions in obese $d b / d b$ mice [35]. This hippocampal microglial activation was enhanced by 5-month administration of a high-fat diet [36]. Obesity not only impacts brain function and structure in adults, but the most worrisome effect involves modifications in the developing brain during childhood and adolescence [37], where the long-term negative consequences on the brain of a life-time being overweight are still unknown.

As opposed to over-nutrition, low-calorie diets, weight reduction or frequent consumption of food rich in antioxidant and antiinflammatory properties, or food patterns with combinations of them, have been associated with decreased markers of systemic and adipose tissue inflammation [38].

Diet studies in humans have shown a link between insulin resistance and cognition [39], as well as T2D glucose regulation abnormalities and cognitive function [40]. Diet interventions that improved insulin resistance have been associated with decreased inflammatory cytokines and improved cognition [41, 42].

\subsubsection{Autophagy}

Autophagy is a catabolic process involved in recycling and degradation of cellular proteins, considered an adaptive response to the increased metabolic demand linked to nutrient starvation. Autophagy efficiency declines with age, and growing evidence shows that enhanced autophagy delays aging and extends longevity, while reduced autophagy leads to premature aging. Autophagy is responsible for the clearance of misfolded proteins, aggregates and the turnover of organelles within the neuron [43]. Evidence suggests that autophagy is deregulated in AD, suggesting that amyloid-beta accumulates in part due to impairment of autophagy degradation [44]. The mammalian target of rapamycin (mTOR), a conserved serine/threonine kinase, is involved in cellular senescence and agedependent diseases, as well as in cellular growth and metabolism in response to nutrients, growth factors and cellular energy conditions. There is evidence that mTOR signaling in the brain affects glucose metabolism, energy production, mitochondrial function and autophagy [45]. All these events are crucial in age-related cognitive decline and AD.

\section{DIETARY COMPONENTS AND SUPPLEMENTS}

\subsection{Vitamins}

Results from the Physicians' Health Study indicated that shortterm treatment with beta-carotene (provitamin A) had no significant effect on cognitive function, but that longer-term (18-year) administration was significantly superior to placebo in a cohort of 4,052 participants [46].

Studies evaluating the impact of vitamin B on cognitive function have produced mixed results. A randomized controlled trial (RCT) of 299 men older than 75 years showed no significant effect of 2-year supplementation with folic acid, vitamin B6, and B12 compared to placebo in improving cognitive function [47]. Likewise, a meta-analysis from 9 RCTs ( $\mathrm{n}=2,835$ participants) cognitively intact at baseline indicated no significant effect of folic acid with or without other B vitamins on cognitive function [48]. Conversely, an RCT of 900 persons with depressive symptoms aged 60-74 years reported that a combination of folic acid and vitamin B12 was significantly superior to placebo for improving cognitive tests delivered by a validated telephone interview [49].

Vitamins $\mathrm{C}$ and $\mathrm{E}$ are potent antioxidants, and their combined effects on cognitive function have been examined in numerous studies in healthy populations. These trials have produced conflicting results. The Women's Health Study including 6,377 women over65 years indicated no significant effect on cognitive function of vitamin E supplementation versus placebo [50]. Likewise, results from the analyses of 616 over65- year participants from the Duke
Established Populations for Epidemiologic Studies showed that vitamins $\mathrm{C}$ and/or $\mathrm{E}$ supplements had no influence on the incidence of dementia or AD [51]. On the contrary, results from the Canadian Study of Health and Aging ( $n=894$ participants aged $\geq 65$ years) indicated that a combination of vitamins $\mathrm{C}$ and $\mathrm{E}$ supplementation significantly decreased the rate of cognitive decline in this cohort [52]. A recent study analyzed the relations of alpha- and gammatocopherol brain concentrations with AD neuropathology among 115 deceased participants of the prospective Rush Memory and Aging Project. Gamma-tocopherol concentrations were associated with lower amyloid load and lower neurofibrillary tangle severity, while concentrations of alpha-tocopherol were not associated with neuropathology, except as modified by gamma-tocopherol: high alpha-tocopherol was associated with higher amyloid load when gamma-tocopherol levels were low and with lower amyloid levels when gamma-tocopherol levels were high. These results reflect the complexity of interconnections of subtypes of tocopherols and suggest the use of gamma-tocopherol in RCTs [53].

The Third National Health and Nutrition Examination Survey (NHANES III), a nationally representative cross-sectional study of the US noninstitutionalized population, reported that vitamin D deficiency was associated with an increased risk of cognitive decline [54]. Conversely, results from the Women's Health Initiative showed no significant effect of vitamin D and calcium supplementation on cognitive function in 2,034 women older than 65 years, followed for a mean of 7.8 years [55].

Large clinical trials of multivitamins supplementation have indicated no significant effects on cognitive function in healthy adults. Results from the Age-Related Eye Disease Study that included 2,166 subjects followed for 6.9 years showed that a combination of antioxidant vitamins (vitamin $\mathrm{E}$, vitamin $\mathrm{C}$, and betacarotene), zinc, and copper had no significant effects on any of six tests of cognitive function [56]. Similarly, the Women's Antioxidant Cardiovascular Study that included 2,824 women with or at risk for CVD who received a combination of vitamin E, betacarotene, and vitamin $\mathrm{C}$ or placebo indicated that the multivitamin supplementation did not alter cognitive function [57].

\subsection{Omega-3 Fatty Acids}

Polyunsaturated fatty acids are key components of neuronal cell membranes, preserving membrane fluidity that is essential for synaptic vesicle fusion and neurotransmitter communication within neural networks. Membrane PUFAs also serve as precursors for lipid messengers, which can participate in signaling processes to promote neuroprotection or induce neuronal failure [58]. Some studies have reported a deficit of PUFAs in the aged brain located in the hippocampus, cortex, and cerebellum, all areas implicated in cognitive and motor functions [59-61]. These deficits may be worse in $\mathrm{AD}$.

Among PUFA, omega-3 fatty acids are the most studied compounds regarding cognitive decline. As with other dietary components, there are dissimilar results for omega-3 supplementation. A systematic literature review showed that existing data favor a role for long-chain omega-3 fatty acids in reducing cognitive decline in older persons without dementia [62]. Nevertheless, several studies not included in this review have shown no significant effect of omega-3 fatty acids on cognitive decline. Results from 1,748 participants with a history of cardio- or cerebrovascular disease of the Supplementation with Folate, vitamin B6 and B12 and/or OMega-3 fatty acids trial reported no significant effects of vitamin $B$ and omega-3 fatty acid supplementation on cognitive function [63]. A double-blind, placebo-controlled trial involving 302 cognitively intact persons older than $\geq 65$ years who were randomly assigned to $1,800 \mathrm{mg} /$ day EPA-DHA, $400 \mathrm{mg}$ /day EPA-DHA, or placebo for 26 weeks indicated no significant differential changes in any of the cognitive domains evaluated for either dose supplementation compared with placebo $[64,65]$. However, the relatively short duration 
of this trial may have precluded observation of a benefit of EPADHA. Findings from a more recent meta-analysis that included results from 3,536 persons older than 60 years without cognitive dysfunction at baseline reported no significant effect on cognitive function of omega-3 fatty supplementation [66]. In a recent epidemiological study among Chinese adults, age significantly modified the association between fish consumption and cognitive change. In persons aged 65 years and older who consumed $\geq 1$ serving/week (i.e., $100 \mathrm{~g}$ ) of fish, the mean annual rate of global cognitive decline was reduced by 0.35 point $(95 \%$ CI: $0.13,0.58)$. Fish consumption was also associated with a slower decline in composite and verbal memory scores. No associations were observed among adults aged 55-64 years [67].

\subsection{Magnesium}

Several studies have shown convincingly that magnesium $(\mathrm{Mg})$ deficiency results in increased production of oxygen-derived free radicals in various tissues, increased free-radical-elicited oxidative tissue damage, increased production of superoxide anion by inflammatory cells, decreased antioxidant enzyme expression and activity, decreased cellular and tissue antioxidant levels, and increased oxygen peroxide production [68-71]. Physiological concentrations of $\mathrm{Mg}$ are essential for synaptic conduction and are required for normal functioning of the nervous system. $\mathrm{Mg}$ exerts various actions on neuronal functions via different pathways. The concentration of $\mathrm{Mg}$ affects many biochemical mechanisms, which consist of N-methyl-D-aspartate (NMDA) receptor response to excitatory amino acids [72], inhibition of calcium channels, calcium influx, and glutamate release, and effects on the stability and viscosity of the cell membrane [73]. The toxic effects of calcium in excitable cells are influenced by intracellular levels of $\mathrm{Mg}$ [74]. $\mathrm{Mg}$ is a physiological calcium antagonist, and this action may contribute to its neuroprotective properties. Because $\mathrm{Mg}$ ion modulates vascular tone by affecting calcium ion concentrations, $\mathrm{Mg}$ deficit produces vasospasm while elevated $\mathrm{Mg}$ causes tone relaxation in cerebral arteries [75]. These mechanisms have important roles in chronic neuronal degeneration and subsequent development of dementia. Hence, the role of $\mathrm{Mg}$ in dementia and other degenerative disorders has been the focus of increased attention in recent years. Several alterations of $\mathrm{Mg}$ metabolism have been found in $\mathrm{AD}$ patients. Previous studies have shown decreased serum $\mathrm{Mg}$ values in patients with severe $\mathrm{AD}$ [76]. We have described a reduction of the active ionized free $\mathrm{Mg}$ concentrations ( $\mathrm{Mg}$ ion) in plasma obtained from $\mathrm{AD}$ patients [77], with $\mathrm{Mg}$-ion levels significantly related to cognitive dysfunction severity. Cilliler et al. [78] also found a negative correlation between serum $\mathrm{Mg}$ levels in $\mathrm{AD}$ patients with the Global Deterioration Scale and the Clinical Dementia Rating, further confirming a possible protective role of $\mathrm{Mg}$, and/or a negative impact of $\mathrm{Mg}$ deficits on cognitive function. Brain tissue from autopsies of $\mathrm{AD}$ patients has lower $\mathrm{Mg}$ concentrations [79]. Although there are no specific trials with $\mathrm{Mg}$ supplements in the prevention or therapy of cognitive disorders, interestingly, treatment of dementia patients with nutritional $\mathrm{Mg}$ support has been suggested to improve memory and other symptoms [80]. Given the prevalence of $\mathrm{Mg}$ inadequacy in the aging population, $\mathrm{Mg}$ supplementation may be of potential help in the prevention and treatment of dementia. However, whether Mg supplementation may exert protective effects against $\mathrm{AD}$ remains to be further elucidated in well-design trials [81].

\subsection{Curcuminoids}

Curcumin is a polyphenolic compound derived from the rhizome of the Curcuma longa. It is contained in culinary curry spice turmeric and used as a coloring agent in food. Traditional Indian medicine considered this compound as an effective therapy for several pathological conditions, ranging from asthma to epilepsy, from gallstone to diabetic wound healing [82]. The potential role of curcumin in dementia originates from an epidemiological study in
2000 by Ganguli et al. [83] reporting a lower prevalence of AD in the Indian population, who consumes a diet rich in curcumincontaining curry, compared to the US population. Afterwards, $\mathrm{Ng}$ et al. [84] found that older healthy persons who consume more frequently curry show a better cognitive performance. Based on these preliminary observations, numerous experimental studies were conducted confirming the potent anti-oxidant and antiinflammatory properties of curcumin and its protection on $\mathrm{AD}$ animal models. In humans, curcumin seems to have a good safety profile in cancer patients (using doses from 500 to $8000 \mathrm{mg}$ /day for three months) [85]. Concerning cognitive decline, three RCTs have been so far completed. In 2008, Baum et al. [86] performed a RCT enrolling 34 patients with $\mathrm{AD}$, randomized to receive either curcumin at two different doses $(1 \mathrm{~g} /$ day or $4 \mathrm{~g} /$ day $)$ or placebo (4 g/day) for six months. All subjects also received $120 \mathrm{mg} /$ day of standardized gingko biloba leaf extract without modifications in previous medications. There was no significant difference between curcumin treatment and placebo in Mini Mental State Examination (MMSE), with no serious side effects reported. Another RCT was reported in 2012 by Ringman et al. [87], recruiting 36 patients with dementia who randomly received $2 \mathrm{~g}$ /day or $4 \mathrm{~g} /$ day of Curcumin $\mathrm{C} 3 \mathrm{Com}-$ plex (95\% of curcuminoids) in two divided doses or placebo for 24 weeks. The trial was extended to 48 weeks as an open-label trial in which patients who received placebo were randomly assigned to 2 $\mathrm{g}$ /day or $4 \mathrm{~g}$ /day of Curcumin C3 Complex, while patients on treatment continued with the same dose assigned at baseline. Primary outcomes were changes at the AD Assessment Scale, cognitive sub-portion (ADAS-Cog) at 24 weeks, and tolerability at 48 weeks. Secondary outcome measures were change at the Neuropsychiatric Inventory (NPI), the AD Cooperative Study Activities of Daily Living (ADCS-ADL), and the MMSE, and modification in plasma and cerebrospinal fluid (CSF) markers. The authors did not observe any significant difference between treatment groups in any of the scores or CSF markers. No serious adverse event was reported. Plasma levels of curcumin were undetectable after single doses, consistent with the low bioavailability of oral curcumin. In 2012, Hishikawa et al. [88] reported a case study of three dementia patients treated with $100 \mathrm{mg} /$ day of curcumin. All three patients experienced a decreased in NPI scores (with reduction in agitation, irritability, anxiety, and apathy) after 12 weeks of therapy. One patient with moderate cognitive decline (12/30 on MMSE) improved his MMSE score by five points. All patients were on antidementia medication (donepezil) before starting curcumin. As mentioned, a major obstacle with curcumin in clinical studies has been the limited bioavailability of supplements, but this problem has been solved with new lipidated formulations [89].

In conclusion, to date there is insufficient evidence to suggest the use of curcumin in dementia patients. There are several ongoing clinical trials evaluating the efficacy of curcumin in AD or MCI, which hopefully will shade more light on the potential therapeutic efficacy of curcumin in dementia.

\subsection{Gingko biloba}

An RCT including 3,069 participants randomized into G. biloba treatment or placebo to determine whether G. biloba supplementation could prevent dementia among older adults who were cognitively intact or had MCI at baseline. Participants were followed for a median of 6.1 years, and the study results indicated no difference in the rate of cognitive decline for the two treatment groups [90].

\subsection{Acetyl-L-Carnitine}

Neuroprotective effects of acetyl-L-carnitine (ALCAR) have been shown in vitro [91], and its effects on cognitive function have been evaluated in several small studies. Results from an RCT of 66 persons aged over 100 years indicated that ALCAR significantly improved MMSE scores compared to placebo [92]. A second smallscale study that included 96 adults older than 70 years indicated that 
ALCAR supplementation resulted in significant improvements in MMSE scores versus placebo [93].

\subsection{Phytoestrogen Compounds}

Soy isoflavones are a group of phytoestrogen compounds, which have been studied seeking alternatives to estrogen treatments. In general, the studies have used mixtures of isoflavones, including genistein and daidzein, making it difficult to discern the effects of specific components of soy phytoestrogen diets on cognition. Studies in cells and animals have shown to reduce AD pathology, and have demonstrated antioxidant properties. However, investigations of soy consumption and phytoestrogen supplements on cognitive function in humans have reported variable and inconclusive results [94].Overall, there is absence of endometrial thickness, circulating hormone concentrations alterations or other important adverse events [95]. Like for hormone replacement therapy, there seems to be and age-dependent effect of phytoestrogen supplements in post-menopausal women (i.e., initial positive cognitive effects, which reverse in elderly women), but this is not addressed by clinical trials; while in men the data are scarce and even more equivocal [94]. Possible reasons to help explain the discrepancies include the use of different isoflavone supplements, at dissimilar doses, and the fact that most are small short-term trials. Importantly, studies reporting no effect of phytoestrogens on cognition have been mostly performed in European cohorts, with low dietary consumption of soy products. Conversely, studies of older Asian populations, with higher consumption of soy-derived foods have shown inverse associations with cognitive decline [94]. S-equol is a selective estrogen receptor (ER)-beta agonist with lower binding activity for ER-alpha (predominantly expressed in the breast and uterus). ER-beta is highly expressed in hippocampal neurons [96]. After oral administration of conjugated isoflavones, daidzein is converted to S-equol by a gut biotransformation. It has been shown that about $70 \%$ of older Japanese persons are "equol producers" [97], which may help explain the different results in Asian vs. Europeans participants. Importantly, in most studies the S-equol producer status was not established.

To overcome some of the limitations in earlier studies, the Women's Isoflavone Soy Health (WISH) trial was performed [98], in which 313 postmenopausal women aged 45-92 years were randomized to receive a daily oral dose of $25 \mathrm{~g}$ of isoflavone-rich soy protein (containing genistein, daidzein, and glycitein) or milk protein-matched placebo. The dose was comparable to that of traditional Asian diets. Cognitive function was evaluated at baseline and after 2.5 years with the changes in a composite score based on 14 neuropsychological tests. There was no significant difference between the groups in cognition changes from baseline. However, women within 5-10 years of menopause in the isoflavone group showed a nonsignificant $(p=0.07)$ trend toward cognitive improvement, and a significant improvement in verbal episodic memory. Urinary S-equol was determined and women classified as non- or intermediate-producers did not have any changes in cognition. Conversely, consistent producers showed a nonsignificant $(\mathrm{p}=0.08)$ trend toward cognitive improvement. However, further studies are needed to confirm these findings. There are no clinical trials of phytoestrogens for the treatment or prevention of $\mathrm{AD}$.

\subsection{Tea and (-)-Epigallocatechin-3-gallate (EGCG)}

In Asian cultures, tea is traditionally view as a natural cognitive stimulator or nootropic because it helps maintain alertness and concentration. This acute effect has been confirmed in controlled studies, as shown in the review by Einother and Martens [99]. Based on these observations, it has been proposed that regular tea drinking may also exert benefits on cognitive performance in the long-term [100]. Tea contains diverse bioactive compounds, such as EGCG, L-theanine, and caffeine, which have antioxidant and antiinflammatory properties that may be neuroprotective $[100,101]$.
Other biological mechanisms by which tea may exert neuroprotective actions include regulation and production of stress hormones, inhibition of acetylcholinesterase, and regulation of brain neurotransmitter systems [101]. Although currently numerous studies suggests that tea consumption has protective actions on cognitive performance in late life, no definitive conclusion can be drawn given the inconsistent findings currently available [102]. More prospective studies are needed perhaps using objective biomarkers of tea intake [103]. Bioactive compounds, such as EGCG and Ltheanine, may have some potential due to their antioxidant properties and anti-amyloidogenic activity in vitro. Nevertheless, the evidence for their use as drugs or medical food is limited [104] and there is no current recommendation for using this compounds in the clinical or public health practice.

\subsection{Resveratrol}

The phytoalexin resveratrol is a polyphenol contained in berries, with the highest source of dietary resveratrol in humans being grapes and red wine [105]. In the past decade, a number of biological properties of resveratrol have been reported, including antioxidant and anti-inflammatory actions [106]. Initially, effects of resveratrol on CVD and cancer were explored, and lately the potential of resveratrol as a neuroprotective compound has been investigated. Even if there are studies in animal models of AD showing that resveratrol administration was associated with, for example, reduced hippocampal neurodegeneration [107], and increased spatial memory performance in non-human primates [108], human clinical trials evaluating the effects of resveratrol on neurodegenerative diseases are currently limited. One placebo-control study in 22 healthy adults showed a dose-dependent (250-500 $\mathrm{mg} /$ day) increase in cerebral blood flow in the prefrontral cortex during cognitive tasks [109]. If these findings are confirmed, this may be an area in which resveratrol possibly have potential clinical benefits. Another study evaluated 23 overweight persons, aged 50-75 years, receiving resveratrol $(200 \mathrm{mg} / \mathrm{d})$ for 26 weeks vs. a group receiving placebo, reporting an improved memory performance and higher functional connectivity of the hippocampus in neuroimaging assessment with resveratrol treatment [110]. There are currently several ongoing clinical trials on resveratrol investigating its potential therapeutic effects on cognitive function in the aging brain, as well as in MCI and $\mathrm{AD}$ [111]. At present, there is no substantial data on toxicity of chronic resveratrol supplementation, although ongoing trials possibly will address this concern.

In summary, there is no sufficiently substantiated support currently for prescribing resveratrol supplements to improve cognitive function in healthy persons or patients with MCI or AD. More studies are still needed to clarify the possible effects, toxicity, and underlying mechanisms of potential neuroprotective effects of resveratrol.

\subsection{Garlic (Allium sativum)}

Extracts of garlic and some of its components have shown to exert antioxidant actions and to protect against amyloid-betainduced neurotoxicity in cells and in experimental animals [112, 113]. Allicin, an organosulfur compound obtained from garlic, has been shown to inhibit cholinesterase enzymes and upregulate levels of acetylcholine in the brain [114], suggesting a potential use in the treatment of AD. However, currently there is no evidence from clinical trials involving patients for any beneficial effects of these compounds. In the Doetinchem Cohort Study, in which 2613 participants aged 43-70 years were examined for cognitive function with a 5-year interval and dietary assessment was performed, higher consumption of allium (onion, garlic, and leek) was associated with worse scores on speed of cognitive processes and cognitive flexibility in cross-sectional analyses. On the contrary, in longitudinal analyses, allium consumption was not associated with cognitive decline [115]. 


\subsection{Caffeine}

The xanthine alkaloid caffeine has been shown to possess antioxidative properties, via quenching of hydroxyl radicals [116], and to decrease amyloid-beta production in animal models of AD [117]. The reduction in amyloid-plaques was associated with a stimulation of protein kinase A activity, increased phosphor-CREB levels, and reduced phosphor-JNK and phosphor-ERK expression in mouse models of AD $[117,118]$. These data suggest that caffeine inhibits proapoptotic pathways and promotes prosurvival cascades in the brain [118].

While coffee and caffeine are recognized to strengthen shortterm memory and cognition, limited research also suggests that long-term use may protect against cognitive decline or dementia. Some studies have shown that caffeine consumption is associated with better cognitive performance and with a slower cognitive decline $[117,119]$. A case-control study among 124 older persons showed that high blood levels of caffeine $(1200 \mathrm{ng} / \mathrm{mL})$ were linked with lack of progression to dementia in patients with MCI [120]. Another study reported a $65 \%$ decrease in incident AD and dementia in persons who had a consumption of 3 to 5 cups of coffee per day [121]. A study among 3,494 men in the Honolulu-Asia Aging Study assessing neuropathologic parameters of dementia, reported that deceased men in the highest quartile of caffeine intake were less likely to have any lesion type when compared to men in the lowest quartile. Nevertheless, coffee and caffeine intake in midlife were not associated with risk of cognitive impairment, overall dementia, AD, vascular dementia, or moderate/high levels of individual neuropathologic lesion types [122].

A meta-analysis of studies exploring the relationship of caffeine consumption and cognitive decline reported a nonsignificant effect [123], but the large heterogeneity across the few number of studies included precluded definitive statements on this topic. Caffeine consumption was associated with slower cognitive decline among older people in Portugal [124]; while no associations were found in a study of men and women from France [125], and in another study from Finland [126]. A longitudinal study of cognitive decline and coffee consumption reported less decline among coffee consumers in women but not in men, and there was no dose response [127]. These findings are similar to those from studies of coffee and dementia showing significance but without demonstrating a doseresponse relationship $[119,121]$.

In summary, coffee intake has been associated with a lower risk of dementia and cognitive impairment in some, but not all, studies. There is hitherto no evidence from RCTs. The heterogeneity of the available evidence (i.e., timing of exposure, confounding, survival bias owing to the cohort age) precludes definitive conclusions regarding the role of coffee in the prevention of dementia. Further studies are needed in order to clarify the role of coffee in the development of cognitive impairment and dementia.

\section{DIETARY PATTERNS}

Dietary patterns in populations of diverse culture, ethnicity, or religious beliefs have been assessed in relation to chronic diseases including atherosclerosis, hypertension, diabetes, and, more recently, dementia and AD. There are various reviews on the numerous epidemiological studies supporting a relationship between diet and $\mathrm{AD}$ [128-131], suggesting that the risk of cognitive decline may be modified by dietary interventions. There is no single dietary or lifestyle intervention definitively proven in RCTs to prevent incident $\mathrm{AD}$. However, epidemiological data suggest that adopting a healthy, balanced diet and lifestyle that improves cardiovascular risk may help delay the onset of $\mathrm{AD}$ due to the potential contribution of vascular disease to dementia [132]. Considering a dietary pattern based on healthy policy guidelines, the Healthy Eating Index-2005 (HEI-2005) (Dietary Guidelines for Americans), two cross-sectional studies $[133,134]$ showed an association between a
HEI-2005 and improvements in cognition in five of the six cohorts assessed. However, two of the longitudinal studies $[135,136]$ followed up to 7.6 years showed no association between HEI-2005 and cognition. Conversely, the study by Wengreen et al. [137], with an 11-year follow-up showed less cognitive decline with an increased HEI score, suggesting that a longer duration may be required to disclose the effect of diet on cognition.

\subsection{Mediterranean Diet}

The Mediterranean diet (MeDiet), a dietary pattern largely consumed among the populations bordering the Mediterranean Sea since millennia, has been widely reported as a model of healthy eating for its contribution to a favorable health status and quality of life. The MeDiet is characterized by high intake of vegetables, legumes, fruits, and cereals; extravirgin olive oil as the main source of fat; low intake of saturated fatty acids; moderately high intake of fish; low to moderate intake of dairy products (mostly cheese or yogurt); low intake of meat and poultry; and regular but moderate intake of alcohol, primarily in the form of red wine and generally during meals [138]. There is not a single Mediterranean dietary pattern because dietary traditions differ between cultures and countries, hence, a MeDiet adherence score has commonly been used to enable a comparison between diets, whereby nine dietary components are given a score of 0 or 1 , with a score of 9 indicating maximum adherence [139]. A greater adherence to the MeDiet has been associated with a reduced incidence of overall mortality, cardiovascular mortality, and/or cardiovascular events incidence; cancer mortality and/or incidence; and incidence of Parkinson's disease and $\mathrm{AD}[131]$.

A recent systematic review of longitudinal cohort studies examining the MeDiet effects on cognition outcomes found that higher adherence to the MeDiet was associated with a significant reduced risk of MCI and AD. Participants in the highest tertile of adherence to MeDiet had $33 \%$ less risk of MCI or $\mathrm{AD}$ when compared to those in the lowest tertile of adherence [129]. The RCT Predimed (Prevención con Dieta Mediterránea), which included adults aged 55-80 years at high cardiovascular risk, showed that participants on a MeDiet supplemented with either extravirgin olive oil or nuts, had a reduced incidence of cardiovascular events compared to participants following a low-fat diet over the 5-year duration of the study [140]. PREDIMED was stopped before the expected time in the original design due to the evident benefit of the intervention arms with MeDiet. Two sub-analyses of samples of the PREDIMED RCT have recently reported that the dietary interventions with MeDiet supplemented with either extravirgin olive oil or nuts were associated with improved cognitive function when compared to a low-fat diet $[141,142]$.

A number of longitudinal population-based studies have examined the effects of adherence to the MeDiet on $\mathrm{AD}$ on cohorts from New York, US [143-147], and France [148, 149]. Two reviews $[131,150]$ assessing the cohort studies concluded that even if there is some evidence that adherence to the MeDiet is associated with a reduced risk of $\mathrm{AD}$, further confirmation in populations with different ethnicities and dietary habits is necessary. The results from two cohort studies from Australia have been published. The Personality and Total Health (PATH) through Life longitudinal study [151] of healthy participants found that MeDiet was not protective for cognitive decline, while the Australian Imaging, Biomarkers and Lifestyle (AIBL) study [152] reported that participants with AD and mild cognitive impairment had lower adherence to the MeDiet than healthy controls. A 7-year longitudinal study [136] examined if adherence to the HEI-2005 or to a MeDiet were associated with cognitive change in a cohort of 3,790 adults aged over 65 years from the ongoing Chicago Health and Aging Project longitudinal study. The results showed that compared to black participants, white participants had higher energy-adjusted MeDiet scores but 
lower HEI-2005 scores. Following adjustments for different confounders, higher MeDiet scores were associated with slower rates of cognitive decline, but no association was found for HEI-2005 scores. The MeDiet pattern also encompasses cultural and lifestyle elements such as social engagement, culinary activities, physical activity, and adequate rest [153]. These lifestyle factors, different from diet (exercise, social engagement, sleeping habits), have shown a positive influence on delaying cognitive decline; perhaps outcomes from MeDiet are due to lifestyle components, including dietary components, but not only attributable to diet. Future studies should consider all MeDiet lifestyle factors into their design.

\subsection{Okinawa Diet}

The Okinawa diet is a low-calorie, nutrient-rich diet original from the Japanese Ryūkyū Islands, of which Okinawa is the largest. The Okinawa diet has received attention over recent years because the residents of Okinawa were found to have some of the longest life expectancies and the highest concentration of centenarians in the world [154]. However, their life expectancy has fallen in recent years, probably because of less use of the traditional local diet and other genetic, lifestyle, and environmental factors.

The traditional Okinawa diet has eighty percent of calories from vegetable sources, whole grains, fruits, legumes (mainly soy), relatively small amounts of fish, and limited amounts of lean meats [155]. The traditional Okinawa diet was twenty percent lower in calories compared to the Japanese average and contained a large proportion of colored vegetables (particularly sweet potatoes - Ipomoea batatas). Sweet potato, the carbohydrate source of Okinawa diet, is rich in antioxidants and has a low-glycemic index, while the Japanese diet takes carbohydrates from rice. Limited consumption of meat, eggs, and dairy products in the traditional Okinawan diet renders it low in saturated fats.

Albeit the effects of the Okinawa diet in relation to longevity have been studied in terms of caloric restriction and nutrient intake $[155,156]$, there is still no solid evidence for the effects on prevention of AD. A study examined the incidence of dementia in a small group of 157 older adults Japanese-Brazilians, aged 70 years and over, who emigrated from Okinawa to Campo Grande in Brazil [157]. The group had a $12.1 \%$ prevalence of dementia, while several other Japanese communities, including a population of 2,217 from Okinawa (evaluated in 1991), had a dementia prevalence of $7.3 \%$. The authors concluded that the dietary pattern modifications with low fish and high meat intake may be associated with increases in dementia, rather than being due to genetic factors. The 9year difference between the studies and the small sample size of the Brazilian community compared to the Okinawa population may have affected the results on the different incidence of dementia. Another study compared circulating micronutrients concentrations from stored serum/plasma in a group of 115 participants from Oregon, US, with 49 participants of an Okinawan group for possible associations with healthy cognitive aging [158]. Participants were aged 85 years and over without cognitive decline. Okinawan elders used fewer vitamin supplements but had similar levels of vitamin B12 and alpha-tocopherol, and lower folate and gamma-tocopherol when compared with elders from Oregon. There was no uniform protective micronutrient pattern between the two groups; hence, the authors concluded that micronutrients other than those examined, or other lifestyle factors, could play an important role in healthy cognitive aging.

\subsection{Caloric Restriction}

Although some population-based studies suggest an association of lower caloric intake with a lower risk of AD [159], older adults tend to have low nutrient intake especially those who progress to early-stage $\mathrm{AD}$, when compared to cognitively intact controls [160]. AD patients frequently develop abnormal eating behaviors (i.e., anorexia nervosa, bulimia); hence, caloric restriction as a treatment for AD patients may be detrimental [159]. Nevertheless, caloric restriction has been associated with improved memory performance in healthy older adults. A systematic review and metaanalysis exploring the relationship between cognitive function and intentional weight loss in overweight and obese participants has been reported [161]. Twelve studies were included in the analyses showing variations in cognitive scores after significant weight loss. Participants' age ranged from 20 to 80 years, with only one study of older participants (aged 50-80 years), and the majority of studies including younger participants (aged 40-60 years); study duration ranged from 28 days to 12.8 months, while the average body mass index (BMI) was 26.1 to $45.5 \mathrm{~kg} / \mathrm{m}^{2}$. There was large heterogeneity among studies in duration, design, and neuropsychological tests. The meta-analysis random effects model for weight loss on memory performance showed significance, even though most studies showed non-significant results. This was attributable to the large sample size of one study and the greater effect size of another study. When studies considering exercise were excluded, the model became non-significant. The extent of the effect of weight loss on memory performance appeared directly associated with baseline BMI. For the attention and executive function domain, applied tests were non homogeneous across studies; however, meta-analysis showed significance, and the exclusion of studies with exercise or bariatric surgery did not change the results. As with memory performance, the extent of weight loss effect on attention and executive function was directly associated with baseline BMI. Cognitive function was assessed immediately after weight loss; hence, the stability of improved cognitive function needs further investigation, as do the effects of metabolic and body composition modifications on cognitive performance. The effects of intentional weight loss on the physical and cognitive function of 50 obese aged 30-59 years and older participants (over 60 years) were examined in a pilot study [162]. The average weight loss of the 21 participants was about $10 \%$ of initial body weight, and weight loss was associated with improved hand-grip strength and cognitive function, with a significant increase in the MMSE scores in older obese participants.

A confounding factor in animal studies is that caloric restriction result in an overall increase in physical activity [163]. This factor might be considered in future human trials evaluating the effects of caloric restriction in delaying the onset of AD. Okinawa diet has been recognized as a caloric-restrictive diet $[155,156]$. Some of the MeDiet populations traditionally use fasting for religious occasions; hence, there may be synergistic effects of caloric restriction with MeDiet, but this would need to be explored in future RCTs. Lifestyle and nutritional factors, including exercise and caloric restriction, are proposed to exert their health benefits through autophagy pathways [164].

\subsection{Vegetarian Diets}

In general, vegetarian diets are adopted following ethical, health, environmental, religious, political, cultural, esthetic, economic, and culinary influences. Vegetarian diets are mostly plantbased diets including fruits, vegetables, cereal grains, nuts, and seeds; mushrooms; with or without dairy products; and eggs. There are several variations of the vegetarian diet, but all avoid red meat consumption. A total vegetarian does not eat all kinds of meat and may also abstain from by-products of animal slaughter (i.e. rennet and gelatin). The first Adventist Health Study project was conducted from 1974 to 1988 with a population of devotees of the Seventh-day Adventist church. The incidence of dementia in those consuming vegetarian diets and meat-eating diets was compared in two cohort sub-studies in groups aged 65 years and over [165]. The first study of 272 California residents matched for age, sex, and living locality included vegan, ovo-lacto-vegetarian, versus two high-meat-eating groups; the results showed that subjects who ate meat (i.e., poultry and fish) were more than twice as likely to become demented as their vegetarian counterparts (RR 2.18), and this was more prominent (RR 2.99) when past meat consumption was 
considered. Another analysis of a group of 2,984 unmatched participants showed no significant difference in the incidence of dementia between vegetarian and meat-eating subjects, with no clear explanation for the difference between the two sub-studies. Although the authors reported a trend toward delayed onset of dementia in vegetarians in both studies, there was no clear evidence that any standardized cognitive assessment was used to assess participants during the study.

\subsection{Ketogenic Diet}

The ketogenic diet (KD) has been associated with neuroprotective effects in some forms of epilepsy, and its effects in neurodegenerative disorders including $\mathrm{AD}$ have been recently investigated [166]. The KD is a high-fat (predominantly saturated), lowcarbohydrate, adequate protein diet, which is used to treat refractory epilepsy in children. Dietary carbohydrates are converted into glucose, which is a particularly important fuel for brain function. The KD mimics starvation by forcing the body to burn fats rather than carbohydrates. If the diet is low in carbohydrates, the liver converts fat into fatty acids and ketone bodies (beta-hydroxybutyrate, acetoacetate, and acetone), which enter into the brain and replace glucose as an energy source. The attained state of ketosis leads to a reduction in the frequency of epileptic seizures [167]. The classic ratio by weight of fat over combined protein and carbohydrate in $\mathrm{KD}$ is $4: 1$. While there is no current evidence of $\mathrm{AD}$ prevention with $\mathrm{KD}$, a small double-blind placebo-controlled study of 20 patients with MCI or AD showed memory scores improvement in patients receiving medium-chain triglycerides in order to elevate plasma ketone bodies concentrations [168]. The study found improvements in memory scores in non- $A P O E \& 4$ patients but not in $A P O E \& 4$ positive patients. A possible explanation of the results is that brain glucose metabolism is impaired in $\mathrm{AD}$, while ketone bodies may provide an alternative energy source. A clinical trial of 152 participants reported similar results [169]. A recent review [170] has underlined some of the possible metabolic mechanisms of the KD, including, decreasing beta-amyloid accumulation and altered mitochondrial function, as well as protection against the neurotoxicity of beta-amyloid, which may result in reduced oxidative stress and neuroinflammation. However, many of the findings with $\mathrm{KD}$ come from animal studies and a solid validation in human trials is still warranted.

High-fat diets, particularly high in saturated fats, are potentially detrimental as mentioned above $[32,33]$. Therefore, this may be in contrast with the potential benefit of ketone bodies. A study tested the effects of two high-fat diets, one rich in PUFA vs. a diet rich in SFA on serum beta-hydroxybutyrate, insulin sensitivity, and lipid profiles in twenty healthy adults. The PUFA-rich diet induced a greater level of ketosis and was associated with improvement in insulin sensitivity, without altering low-density cholesterol, compared to SFA-rich diet [171].

\subsection{Low-Copper Diet}

Copper $(\mathrm{Cu})$ is an essential element in the body. Even if plasma copper $(\mathrm{Cu})$ levels relates to $\mathrm{Cu}$ intake with diet, the origin of free $\mathrm{Cu}$ is still under discussion, potentially depending on inflammation status. There is recent evidence indicating that altered $\mathrm{Cu}$ metabolism may be one of the pathogenic mechanisms of AD and other neurodegenerative diseases [172]. A longitudinal study involving 3,718 participants showed that high intakes of copper, mostly from copper supplements, in combination with a high-fat diet resulted in more rapid cognitive decline in the general population after 5.5 years follow-up [173]. Conversely, in a study of 32 patients with mild to moderate $\mathrm{AD}$, despite the fact that all patients had $\mathrm{Cu}$ levels in the physiological range $(65-165 \mathrm{mcg} / \mathrm{dL})$, patients with low plasma $\mathrm{Cu}$ had significantly higher ADAS-cog scores [174]. This is important because the general population is frequently in contact with $\mathrm{Cu}$, and the promotion of a low- $\mathrm{Cu}$ diet may potentially reduce the risk of $\mathrm{AD}$ [175]. However, there is no conclusive evidence that depletion or supplementation of $\mathrm{Cu}$ may modify $\mathrm{AD}$ incidence or pathology. Post-mortem studies reported decreased or unchanged levels of $\mathrm{Cu}$ in the hippocampus, cerebellum, cortex, or amygdala in patients with $\mathrm{AD}$ when compared to controls [176]. Further research is certainly needed to define the role of $\mathrm{Cu}$ homeostasis in the brain during $\mathrm{AD}$, but until then it is wise to advise o low dietary intake of $\mathrm{Cu}$, including drinking water, and avoidance of $\mathrm{Cu}$ supplements, regardless of the current lack of consistent data.

\subsection{Dietary Approaches to Stop Hypertension (DASH)}

This is a dietary balanced eating plan, rich in fruits, vegetable, and low-fat dairy, with reduced total fats and sugar-sweetened products, which effectively lowers blood pressure, improves lipid profiles, and reduces incident cardiovascular events [177]. Although DASH was not specifically design to influence cognitive function, its positive effects on vascular health may be neuroprotective.

A recent study investigated the associations between DASH and MeDiet adherence with age-related cognitive changes prospectively in 3,831 participants older than 65 years residents of Cache County, UT, followed for over 11 years. Higher adherence to DASH and MeDiet and higher consumption of whole grains, nuts and legumes were significantly associated with higher average scores of modified MMSE after follow-up [178]. A recent study reported similar findings combining the two dietary patterns (MeDiet-DASH, or MIND), following a cohort of 960 participants of the Memory and Aging Project for a mean of 4.7 years. After adjusting for confounders, the MIND score was positively associated with slower decline in global cognitive score and with five single cognitive domains. The differences in decline rates for those at the highest tertile of MIND adherence score vs. the lowest tertile was equivalent to being 7.5 years younger in age [179]. The same group of researchers examined the effects of the hybrid diet on incident AD in 923 participants, aged 58-98 years, followed on average 4.5 years. Adjusted proportional hazards models showed significant reduction in incident $\mathrm{AD}$ for the second and third tertile of adherence scores to MIND diet vs. the lowest tertile, whereas only the third tertiles of DASH and MeDiet were associated with lower AD rates. Therefore, both patterns are protective but the highest the adherence to both (or MIND diet), the better the prevention of AD [180]. Replications of these results with DASH and MIND are required to verify their relevance to brain health.

\subsection{Paleolithic Diet}

The Paleolithic diet is also called the hunter-gatherer diet, ancestral diet, primal diet, evolutionary diet, and caveman diet. This diet is based on foods that were eaten prior to agriculture and animal farming (e.g., meat, fish, shellfish, eggs, tree nuts, vegetables, roots, fruit, berries, mushrooms) during the Paleolithic Era, excluding foods resulting from agriculture or animal farming (grains, dairy, beans/legumes, potatoes, sugar, meats, and manufactured foods). Food consumption was based on availability in a specific location as part of a nomadic lifestyle; hence diets could vary considerably from season to season. A recent systematic review of four RCTs involving 159 participants found that the Paleolithic diet resulted in greater short-term improvements on metabolic syndrome components compared to guideline-based control diets [181]. A study of 20 overweight postmenopausal women compared the effects of a 6-month modified Paleolithic diet vs. a standard diet following the Nordic Nutrition Recommendations on parameters of functional MRI with episodic memory tasks, and weight loss. There was a significant improvement in episodic memory performance after the dietary interventions, without differences between diets, which was associated with increased hippocampal activity, decreased waist circumference, and reduced plasma FFA [182]. There are still no studies on the effects of a Paleolithic diet and the pre- 
vention of $\mathrm{AD}$, despite the higher frequency of distribution of the $A P O E \& 4$ allele in many of the hunter-gatherer populations currently living around the world [183]. However, the available data warrant additional evaluations of the brain health benefits of Paleolithic nutrition.

\section{CONCLUSION}

While there seems to be no significant benefit in preventing further cognitive decline with nutritional interventions for patients with established dementia or $\mathrm{AD}$, research on the potential of nutritional interventions to prevent or delay cognitive impairment and the development of AD is rapidly growing, with various clinical trials recently being completed or underway. Results from largescale epidemiologic studies and clinical trials generally do not support a clear role for most of the nutritional and dietary factors that have been examined for prevention of cognitive decline or AD. It is reasonable to conclude that the influence of dietary supplementation on cognitive function in healthy middle-aged and older adults and in those with cognitive decline or $\mathrm{AD}$ remains at best uncertain, and further research is warranted to clarify the benefits of these approaches.

The role of the Mediterranean diet in cardiovascular health is well established, and there is moderately convincing evidence primarily from population/epidemiologic studies (the number of studies is still small) that adherence to this dietary pattern is associated with a reduced risk of $\mathrm{AD}$; however, further confirmation in prospective study populations and RCTs with longer follow-up, with different ethnicities and different dietary habits is warranted, as well. There is currently no evidence to validate any effects of the vegetarian, Okinawa, ketogenic, Paleolithic or caloric restriction diets on the prevention of cognitive decline or AD.

The literature is beginning to emphasize the importance of studying dietary patterns or whole of diet approaches rather than individual foods or nutrients due to likely synergistic effects of nutrient combinations. For example, a dietary pattern high in saturated fatty acids but also high in monounsaturated fatty acids may result in an overall null effect. Hence, studying dietary patterns and evaluating food combinations may provide insights into synergistic actions of some nutrient combinations with respect to delaying the onset of cognitive decline and dementia.

\section{CONFLICT OF INTEREST}

The authors confirm that this article content has no conflict of interest.

\section{ACKNOWLEDGEMENTS}

Both authors contributed substantially to the intellectual content, literature search and reviewing, writing and critically reviewing the manuscript.

\section{REFERENCES}

[1] 2014 Alzheimer's disease facts and figures. Alzheimers Dement 2014; 10: e47-92.

[2] Prince MJ, Wu F, Guo Y, et al. The burden of disease in older people and implications for health policy and practice. Lancet 2015; 385: 549-62.

[3] Mathers CD, Stevens GA, Boerma T, White RA, Tobias MI. Causes of international increases in older age life expectancy. Lancet $2015 ; 385$ : 540-8.

[4] Feldman HH, Haas M, Gandy S, et al. Alzheimer's disease research and development: A call for a new research roadmap. Ann N Y Acad Sci 2014; 1313: 1-16.

[5] Halil M, Cemal KM, Emin KM, Yesil Y, Cruz JAJ. Cognitive aspects of frailty: Mechanisms behind the link between frailty and cognitive impairment. J Nutr Health Aging 2015; 19: 276-83.

[6] Norton S, Matthews FE, Barnes DE, Yaffe K, Brayne C. Potential for primary prevention of alzheimer's disease: An analysis of population-based data. Lancet Neurol 2014; 13: 788-94.
[7] Hakim AM. Perspective: Silent, but preventable, perils. Nature 2014; 510: S12.

[8] Meydani M. Antioxidants and cognitive function. Nutr Rev 2001; 59: S75-80.

[9] Farooqui AA, Ong WY, Horrocks LA, Chen P, Farooqui T. Comparison of biochemical effects of statins and fish oil in brain: The battle of the titans. Brain Res Rev 2007; 56: 443-71.

[10] Lukiw WJ, Bazan NG. Docosahexaenoic acid and the aging brain. J Nutr 2008; 138: 2510-4.

[11] Jacobs DR, Jr., Orlich MJ. Diet pattern and longevity: Do simple rules suffice? A commentary. Am J Clin Nutr 2014; 100 Suppl 1: 313S-9S.

[12] Kapogiannis D, Mattson MP. Disrupted energy metabolism and neuronal circuit dysfunction in cognitive impairment and alzheimer's disease. Lancet Neurol 2011; 10: 187-98.

[13] Mao P, Reddy PH. Aging and amyloid beta-induced oxidative DNA damage and mitochondrial dysfunction in alzheimer's disease: Implications for early intervention and therapeutics. Biochim Biophys Acta 2011; 1812: 1359-70.

[14] Heneka MT, Carson MJ, El Khoury J, et al. Neuroinflammation in alzheimer's disease. Lancet Neurol 2015; 14: 388-405.

[15] Cherry JD, Olschowka JA, O'Banion MK. Neuroinflammation and $\mathrm{m} 2$ microglia: The good, the bad, and the inflamed. J Neuroinflamm 2014; 11: 98.

[16] Karran E, Mercken M, De Strooper B. The amyloid cascade hypothesis for alzheimer's disease: An appraisal for the development of therapeutics. Nat Rev Drug Discov 2011; 10: 698712.

[17] Yasuno F, Ota M, Kosaka J, et al. Increased binding of peripheral benzodiazepine receptor in alzheimer's disease measured by positron emission tomography with [11c]daa1106. Biol Psychiatry 2008; 64: 835-41.

[18] Yuste JE, Tarragon E, Campuzano CM, Ros-Bernal F. Implications of glial nitric oxide in neurodegenerative diseases. Front Cell Neurosci 2015; 9: 322 .

[19] Cortes-Canteli M, Zamolodchikov D, Ahn HJ, Strickland S, Norris EH. Fibrinogen and altered hemostasis in alzheimer's disease. J Alzheimers Dis 2012; 32: 599-608.

[20] Bacchetti T, Vignini A, Giulietti A, et al. Higher levels of oxidized low density lipoproteins in alzheimer's disease patients: Roles for platelet activating factor acetyl hydrolase and paraoxonase-1. J Alzheimers Dis 2015; 46: 179-86.

[21] de la Torre JC. Vascular risk factors: A ticking time bomb to alzheimer's disease. Am J Alzheimers Dis Other Demen 2013; 28: 551-9.

[22] Morley JE. The metabolic syndrome and aging. J Gerontol A Biol Sci Med Sci 2004; 59: 139-42.

[23] Aguilar M, Bhuket T, Torres S, Liu B, Wong RJ. Prevalence of the metabolic syndrome in the united states, 2003-2012. JAMA 2015; 313: 1973-4.

[24] Sepulveda J, Murray C. The state of global health in 2014. Science 2014; 345 : 1275-8.

[25] Emmerzaal TL, Kiliaan AJ, Gustafson DR. 2003-2013: A decade of body mass index, alzheimer's disease, and dementia. J Alzheimers Dis 2015; 43: 739-55.

[26] Jahangiri A, Wilson PG, Hou T, Brown A, King VL, Tannock LR. Serum amyloid $\mathrm{a}$ is found on apo-b-containing lipoproteins in obese humans with diabetes. Obesity (Silver Spring) 2013; 21: 993 6.

[27] Gustafson DR, Karlsson C, Skoog I, Rosengren L, Lissner L, Blennow K. Mid-life adiposity factors relate to blood-brain barrier integrity in late life. J Intern Med 2007; 262: 643-50.

[28] Kanoski SE, Zhang Y, Zheng W, Davidson TL. The effects of a high-energy diet on hippocampal function and blood-brain barrier integrity in the rat. J Alzheimers Dis 2010; 21: 207-19.

[29] Grant RW, Dixit VD. Adipose tissue as an immunological organ Obesity (Silver Spring) 2015; 23: 512-8

[30] Harford KA, Reynolds CM, McGillicuddy FC, Roche HM. Fats, inflammation and insulin resistance: Insights to the role of macrophage and t-cell accumulation in adipose tissue. Proc Nutr Soc 2011; 70: 408-17.

[31] Koyama A, O'Brien J, Weuve J, Blacker D, Metti AL, Yaffe K. The role of peripheral inflammatory markers in dementia and alzheimer's disease: A meta-analysis. J Gerontol A Biol Sci Med Sci 2013; 68: 433-40. 
[32] Velloso LA, Folli F, Saad MJ. Tlr4 at the crossroads of nutrients, gut microbiota, and metabolic inflammation. Endocr Rev 2015; 36: 245-71.

[33] Gregor MF, Hotamisligil GS. Inflammatory mechanisms in obesity. Annu Rev Immunol 2011; 29: 415-45.

[34] Miller AA, Spencer SJ. Obesity and neuroinflammation: A pathway to cognitive impairment. Brain Behav Immun 2014; 42: $10-21$.

[35] Erion JR, Wosiski-Kuhn M, Dey A, et al. Obesity elicits interleukin 1-mediated deficits in hippocampal synaptic plasticity. J Neurosci 2014; 34: 2618-31.

[36] Tucsek Z, Toth $\mathrm{P}$, Sosnowska D, et al. Obesity in aging exacerbates blood-brain barrier disruption, neuroinflammation, and oxidative stress in the mouse hippocampus: Effects on expression of genes involved in beta-amyloid generation and alzheimer's disease. J Gerontol A Biol Sci Med Sci 2014; 69: 1212-26.

[37] Liang J, Matheson BE, Kaye WH, Boutelle KN. Neurocognitive correlates of obesity and obesity-related behaviors in children and adolescents. Int J Obes (Lond) 2014; 38: 494-506.

[38] Calder PC, Ahluwalia N, Brouns F, et al. Dietary factors and lowgrade inflammation in relation to overweight and obesity. Br J Nutr 2011; 106 Suppl 3: S5-78.

[39] Cholerton B, Baker LD, Craft S. Insulin, cognition, and dementia. Eur J Pharmacol 2013; 719: 170-9.

[40] Geijselaers SL, Sep SJ, Stehouwer CD, Biessels GJ. Glucose regulation, cognition, and brain mri in type 2 diabetes: A systematic review. Lancet Diabetes Endocrinol 2015; 3: 75-89.

[41] Kelly KR, Haus JM, Solomon TP, et al. A low-glycemic index diet and exercise intervention reduces tnf(alpha) in isolated mononuclear cells of older, obese adults. J Nutr 2011; 141: 108994.

[42] Bayer-Carter JL, Green PS, Montine TJ, et al. Diet intervention and cerebrospinal fluid biomarkers in amnestic mild cognitive impairment. Arch Neurol 2011; 68: 743-52.

[43] Martinez-Vicente M. Autophagy in neurodegenerative diseases: From pathogenic dysfunction to therapeutic modulation. Semin Cell Dev Biol 2015; 40: 115-26.

[44] Jaeger PA, Wyss-Coray T. Beclin 1 complex in autophagy and alzheimer disease. Arch Neurol 2010; 67: 1181-4

[45] Martinez de Morentin PB, Martinez-Sanchez N, Roa J, et al. Hypothalamic mTOR: the rookie energy sensor. Curr Mol Med 2014; 14: 3-21.

[46] Grodstein F, Kang JH, Glynn RJ, Cook NR, Gaziano JM. A randomized trial of beta carotene supplementation and cognitive function in men: The physicians' health study II. Arch Intern Med 2007; 167: 2184-90.

[47] Ford AH, Flicker L, Alfonso H, et al. Vitamins b(12), b(6), and folic acid for cognition in older men. Neurology 2010; 75: 1540-7.

[48] Wald DS, Kasturiratne A, Simmonds M. Effect of folic acid, with or without other $\mathrm{b}$ vitamins, on cognitive decline: Meta-analysis of randomized trials. Am J Med 2010; 123: 522-7 e522.

[49] Walker JG, Batterham PJ, Mackinnon AJ, et al. Oral folic acid and vitamin b-12 supplementation to prevent cognitive decline in community-dwelling older adults with depressive symptoms--the beyond ageing project: A randomized controlled trial. Am J Clin Nutr 2012; 95: 194-203.

[50] Kang JH, Cook N, Manson J, Buring JE, Grodstein F. A randomized trial of vitamin e supplementation and cognitive function in women. Arch Intern Med 2006; 166: 2462-8.

[51] Fillenbaum GG, Kuchibhatla MN, Hanlon JT, et al. Dementia and alzheimer's disease in community-dwelling elders taking vitamin c and/or vitamin e. Ann Pharmacother 2005; 39: 2009-14.

[52] Maxwell CJ, Hicks MS, Hogan DB, Basran J, Ebly EM. Supplemental use of antioxidant vitamins and subsequent risk of cognitive decline and dementia. Dement Geriatr Cogn Disord 2005; 20: 45-51.

[53] Morris MC, Schneider JA, Li H, et al. Brain tocopherols related to alzheimer's disease neuropathology in humans. Alzheimers Dement 2015; 11: 32-9.

[54] Llewellyn DJ, Lang IA, Langa KM, Melzer D. Vitamin d and cognitive impairment in the elderly U.S. Population. J Gerontol A Biol Sci Med Sci 2011; 66: 59-65.

[55] Rossom RC, Espeland MA, Manson JE, et al. Calcium and vitamin $\mathrm{d}$ supplementation and cognitive impairment in the women's health initiative. J Am Geriatr Soc 2012; 60: 2197-205.
[56] Yaffe K, Clemons TE, McBee WL, Lindblad AS. Impact of antioxidants, zinc, and copper on cognition in the elderly: A randomized, controlled trial. Neurology 2004; 63: 1705-7.

[57] Kang JH, Cook NR, Manson JE, Buring JE, Albert CM, Grodstein F. Vitamin e, vitamin c, beta carotene, and cognitive function among women with or at risk of cardiovascular disease: The women's antioxidant and cardiovascular study. Circulation 2009; 119: 2772-80.

[58] Bazan NG. Lipid signaling in neural plasticity, brain repair, and neuroprotection. Mol Neurobiol 2005; 32: 89-103.

[59] Little SJ, Lynch MA, Manku M, Nicolaou A. Docosahexaenoic acid-induced changes in phospholipids in cortex of young and aged rats: A lipidomic analysis. Prostaglandins Leukot Essent Fatty Acids 2007; 77: 155-62.

[60] Janssen CI, Kiliaan AJ. Long-chain polyunsaturated fatty acids (lcpufa) from genesis to senescence: The influence of lcpufa on neural development, aging, and neurodegeneration. Prog Lipid Res 2014; 53: 1-17.

[61] Liu JJ, Green P, John Mann J, Rapoport SI, Sublette ME. Pathways of polyunsaturated fatty acid utilization: Implications for brain function in neuropsychiatric health and disease. Brain Res 2015; 1597: 220-46.

[62] Fotuhi M, Mohassel P, Yaffe K. Fish consumption, long-chain omega-3 fatty acids and risk of cognitive decline or alzheimer disease: A complex association. Nat Clin Pract Neurol 2009; 5 : 140-52.

[63] Andreeva VA, Kesse-Guyot E, Barberger-Gateau P, Fezeu L, Hercberg S, Galan P. Cognitive function after supplementation with $b$ vitamins and long-chain omega-3 fatty acids: Ancillary findings from the su.Fol.Om3 randomized trial. Am J Clin Nutr 2011; 94: 278-86.

[64] van de Rest O, Geleijnse JM, Kok FJ, et al. Effect of fish oil on cognitive performance in older subjects: A randomized, controlled trial. Neurology 2008; 71: 430-8.

[65] van de Rest O, Geleijnse JM, Kok FJ, et al. Effect of fish-oil supplementation on mental well-being in older subjects: A randomized, double-blind, placebo-controlled trial. Am J Clin Nutr 2008; 88: 706-13.

[66] Sydenham E, Dangour AD, Lim WS. Omega 3 fatty acid for the prevention of cognitive decline and dementia. Cochrane Database Syst Rev 2012; 6: CD005379.

[67] Qin B, Plassman BL, Edwards LJ, Popkin BM, Adair LS, Mendez MA. Fish intake is associated with slower cognitive decline in chinese older adults. J Nutr 2014; 144: 1579-85

[68] Barbagallo M, Dominguez LJ. Magnesium and aging. Curr Pharm Des 2010; 16: 832-9.

[69] Ames BN, Atamna H, Killilea DW. Mineral and vitamin deficiencies can accelerate the mitochondrial decay of aging. Mol Aspects Med 2005; 26: 363-78.

[70] Hans CP, Chaudhary DP, Bansal DD. Effect of magnesium supplementation on oxidative stress in alloxanic diabetic rats. Magnes Res 2003; 16: 13-19.

[71] Manuel Y, Keenoy B, Moorkens G, Vertommen J, Noe M, Neve J, De Leeuw I. Magnesium status and parameters of the oxidantantioxidant balance in patients with chronic fatigue: Effects of supplementation with magnesium. J Am Coll Nutr 2000; 19: 37482.

[72] Choi DW. Ionic dependence of glutamate neurotoxicity. J Neurosci 1987; 7: 369-79.

[73] Barbagallo M, Belvedere M, Dominguez LJ. Magnesium homeostasis and aging. Magnes Res 2009; 22: 235-46.

[74] Alvarez-Leefmans FJ, Giraldez F, Gamino SM. Intracellular free magnesium in excitable cells: Its measurement and its biologic significance. Can J Physiol Pharmacol 1987; 65: 915-25.

[75] Altura BT, Altura BM. Withdrawal of magnesium causes vasospasm while elevated magnesium produces relaxation of tone in cerebral arteries. Neurosci Lett 1980; 20: 323-7.

[76] Lemke MR. Plasma magnesium decrease and altered calcium/magnesium ratio in severe dementia of the alzheimer type. Biol Psychiatry 1995; 37: 341-3.

[77] Barbagallo M, Belvedere M, Di Bella G, Dominguez LJ. Altered ionized magnesium levels in mild-to-moderate alzheimer's disease. Magnes Res 2011; 24: S115-21.

[78] Cilliler AE, Ozturk S, Ozbakir S. Serum magnesium level and clinical deterioration in alzheimer's disease. Gerontology 2007; 53 : 419-22. 
[79] Durlach J. Magnesium depletion and pathogenesis of alzheimer's disease. Magnes Res 1990; 3: 217-8.

[80] Glick JL. Dementias: The role of magnesium deficiency and an hypothesis concerning the pathogenesis of alzheimer's disease. Med Hypotheses 1990; 31: 211-25.

[81] Ozturk S, Cillier AE. Magnesium supplementation in the treatment of dementia patients. Med Hypotheses 2006; 67: 1223-5.

[82] Aggarwal BB, Sundaram C, Malani N, Ichikawa H. Curcumin: The indian solid gold. Adv Exp Med Biol 2007; 595: 1-75.

[83] Ganguli M, Chandra V, Kamboh MI, et al. Apolipoprotein e polymorphism and alzheimer disease: The indo-us cross-national dementia study. Arch Neurol 2000; 57: 824-30.

[84] Ng TP, Chiam PC, Lee T, Chua HC, Lim L, Kua EH. Curry consumption and cognitive function in the elderly. Am J Epidemiol 2006; 164: 898-906.

[85] Cheng AL, Hsu CH, Lin JK, et al. Phase i clinical trial of curcumin, a chemopreventive agent, in patients with high-risk or pre-malignant lesions. Anticancer Res 2001; 21: 2895-900.

[86] Baum L, Lam CW, Cheung SK, et al. Six-month randomized, placebo-controlled, double-blind, pilot clinical trial of curcumin in patients with alzheimer disease. J Clin Psychopharmacol 2008; 28: 110-3.

[87] Ringman JM, Frautschy SA, Teng E, et al. Oral curcumin for alzheimer's disease: Tolerability and efficacy in a 24-week randomized, double blind, placebo-controlled study. Alzheimers Res Ther 2012; 4: 43.

[88] Hishikawa N, Takahashi Y, Amakusa Y, et al. Effects of turmeric on alzheimer's disease with behavioral and psychological symptoms of dementia. Ayu 2012; 33: 499-504.

[89] Begum AN, Jones MR, Lim GP, et al. Curcumin structurefunction, bioavailability, and efficacy in models of neuroinflammation and alzheimer's disease. J Pharmacol Exp Ther 2008; 326: 196-208.

[90] Snitz BE, O'Meara ES, Carlson MC, et al. Ginkgo biloba for preventing cognitive decline in older adults: A randomized trial. JAMA 2009; 302: 2663-70.

[91] Owen L, Sunram-Lea SI. Metabolic agents that enhance atp can improve cognitive functioning: A review of the evidence for glucose, oxygen, pyruvate, creatine, and 1-carnitine. Nutrients 2011; 3: 735-55.

[92] Malaguarnera M, Vacante M, Avitabile T, Cammalleri L, Motta M. L-carnitine supplementation reduces oxidized ldl cholesterol in patients with diabetes. Am J Clin Nutr 2009; 89: 71-6.

[93] Malaguarnera M, Gargante MP, Cristaldi E, et al. Acetyl 1-carnitine (alc) treatment in elderly patients with fatigue. Arch Gerontol Geriatr 2008; 46: 181-90.

[94] Soni M, Rahardjo TB, Soekardi R, et al. Phytoestrogens and cognitive function: A review. Maturitas 2014; 77: 209-20.

[95] Alekel DL, Genschel U, Koehler KJ, et al. Soy isoflavones for reducing bone loss study: Effects of a 3-year trial on hormones, adverse events, and endometrial thickness in postmenopausal women. Menopause 2015; 22: 185-97.

[96] Handa RJ, Mani SK, Uht RM. Estrogen receptors and the regulation of neural stress responses. Neuroendocrinology 2012; 96: 111-8.

[97] Jackson RL, Greiwe JS, Schwen RJ. Emerging evidence of the health benefits of s-equol, an estrogen receptor beta agonist. Nutr Rev 2011; 69: 432-48.

[98] Henderson VW, St John JA, Hodis HN, et al. Long-term soy isoflavone supplementation and cognition in women: A randomized, controlled trial. Neurology 2012; 78: 1841-8.

[99] Einother SJ, Martens VE. Acute effects of tea consumption on attention and mood. Am J Clin Nutr 2013; 98: S1700-8.

[100] Feng L, Li J, Ng TP, Lee TS, Kua EH, Zeng Y. Tea drinking and cognitive function in oldest-old chinese. J Nutr Health Aging 2012; 16: 754-8.

[101] Chen D, Milacic V, Chen MS, et al. Tea polyphenols, their biological effects and potential molecular targets. Histol Histopathol 2008; 23: 487-96.

[102] Song J, Xu H, Liu F, Feng L. Tea and cognitive health in late life: Current evidence and future directions. J Nutr Health Aging 2012; 16: 31-4.

[103] Perez-Jimenez J, Hubert J, Hooper L, et al. Urinary metabolites as biomarkers of polyphenol intake in humans: A systematic review. Am J Clin Nutr 2010; 92: 801-9.
[104] Jayasena T, Poljak A, Smythe G, Braidy N, Munch G, Sachdev P. The role of polyphenols in the modulation of sirtuins and other pathways involved in alzheimer's disease. Ageing Res Rev 2013; 12: $867-83$.

[105] Baur JA, Sinclair DA. Therapeutic potential of resveratrol: The in vivo evidence. Nat Rev Drug Discov 2006; 5: 493-506.

[106] Park EJ, Pezzuto JM. The pharmacology of resveratrol in animals and humans. Biochim Biophys Acta 2015; 1852: 1071-113.

[107] Kim D, Nguyen MD, Dobbin MM, et al. Sirt1 deacetylase protects against neurodegeneration in models for alzheimer's disease and amyotrophic lateral sclerosis. EMBO J 2007; 26: 3169-79.

[108] Dal-Pan A, Pifferi F, Marchal J, Picq JL, Aujard F. Cognitive performances are selectively enhanced during chronic caloric restriction or resveratrol supplementation in a primate. PLoS One 2011; 6: e16581.

[109] Kennedy DO, Wightman EL, Reay JL, et al. Effects of resveratrol on cerebral blood flow variables and cognitive performance in humans: A double-blind, placebo-controlled, crossover investigation. Am J Clin Nutr 2010; 91: 1590-7.

[110] Witte AV, Kerti L, Margulies DS, Floel A. Effects of resveratrol on memory performance, hippocampal functional connectivity, and glucose metabolism in healthy older adults. J Neurosci 2014; 34 : 7862-70.

[111] Tome-Carneiro J, Larrosa M, Gonzalez-Sarrias A, Tomas-Barberan FA, Garcia-Conesa MT, Espin JC. Resveratrol and clinical trials: The crossroad from in vitro studies to human evidence. Curr Pharm Des 2013; 19: 6064-93.

[112] Ray B, Chauhan NB, Lahiri DK. The "aged garlic extract:" (age) and one of its active ingredients s-allyl-l-cysteine (sac) as potential preventive and therapeutic agents for alzheimer's disease (ad). Curr Med Chem 2011; 18: 3306-13.

[113] Jeong JH, Jeong HR, Jo YN, Kim HJ, Shin JH, Heo HJ Ameliorating effects of aged garlic extracts against abeta-induced neurotoxicity and cognitive impairment. BMC Complement Altern Med 2013; 13: 268.

[114] Kumar S. Dual inhibition of acetylcholinesterase and butyrylcholinesterase enzymes by allicin. Indian J Pharmacol 2015; 47: 444-6.

[115] Nooyens AC, Bueno-de-Mesquita HB, van Boxtel MP, van Gelder BM, Verhagen H, Verschuren WM. Fruit and vegetable intake and cognitive decline in middle-aged men and women: The doetinchem cohort study. Br J Nutr 2011; 106: 752-61.

[116] Azam S, Hadi N, Khan NU, Hadi SM. Antioxidant and prooxidant properties of caffeine, theobromine and xanthine. Med Sci Monit 2003; 9: BR325-30.

[117] Arendash GW, Mori T, Cao C, et al. Caffeine reverses cognitive impairment and decreases brain amyloid-beta levels in aged alzheimer's disease mice. J Alzheimers Dis 2009; 17: 661-80.

[118] Zeitlin R, Patel S, Burgess S, Arendash GW, Echeverria V. Caffeine induces beneficial changes in pka signaling and jnk and erk activities in the striatum and cortex of alzheimer's transgenic mice. Brain Res 2011; 1417: 127-36.

[119] van Gelder BM, Buijsse B, Tijhuis M, et al. Coffee consumption is inversely associated with cognitive decline in elderly european men: The fine study. Eur J Clin Nutr 2007; 61: 226-32.

[120] Cao C, Loewenstein DA, Lin X, et al. High blood caffeine levels in mci linked to lack of progression to dementia. J Alzheimers Dis 2012; 30: 559-72.

[121] Eskelinen MH, Ngandu T, Tuomilehto J, Soininen H, Kivipelto M. Midlife coffee and tea drinking and the risk of late-life dementia: A population-based caide study. J Alzheimers Dis 2009; 16: 85-91.

[122] Gelber RP, Petrovitch H, Masaki KH, Ross GW, White LR. Coffee intake in midlife and risk of dementia and its neuropathologic correlates. J Alzheimers Dis 2011; 23: 607-15.

[123] Santos C, Costa J, Santos J, Vaz-Carneiro A, Lunet N. Caffeine intake and dementia: Systematic review and meta-analysis. J Alzheimers Dis 2010; 20 Suppl 1: S187-204.

[124] Santos C, Lunet N, Azevedo A, de Mendonca A, Ritchie K, Barros $\mathrm{H}$. Caffeine intake is associated with a lower risk of cognitive decline: A cohort study from portugal. J Alzheimers Dis 2010; 20 Suppl 1: S175-85.

[125] Ritchie K, Carriere I, de Mendonca A, et al. The neuroprotective effects of caffeine: A prospective population study (the three city study). Neurology 2007; 69: 536-45.

[126] Laitala VS, Kaprio J, Koskenvuo M, Raiha I, Rinne JO, Silventoinen K. Coffee drinking in middle age is not associated 
with cognitive performance in old age. Am J Clin Nutr 2009; 90 : 640-6.

[127] Arab L, Biggs ML, O'Meara ES, Longstreth WT, Crane PK, Fitzpatrick AL. Gender differences in tea, coffee, and cognitive decline in the elderly: The cardiovascular health study. J Alzheimers Dis 2011; 27: 553-66.

[128] Scheltens P. Nutrition and dementia. Eur J Neurol 2009; 16 Suppl 1:iii-iv.

[129] Singh B, Parsaik AK, Mielke MM, et al. Association of mediterranean diet with mild cognitive impairment and alzheimer's disease: A systematic review and meta-analysis. J Alzheimers Dis 2014; 39: 271-82

[130] Alles B, Samieri C, Feart C, Jutand MA, Laurin D, BarbergerGateau P. Dietary patterns: A novel approach to examine the link between nutrition and cognitive function in older individuals. Nutr Res Rev 2012; 25: 207-22.

[131] Sofi F, Abbate R, Gensini GF, Casini A. Accruing evidence on benefits of adherence to the mediterranean diet on health: An updated systematic review and meta-analysis. Am J Clin Nutr 2010; 92: 1189-96.

[132] Mucke L. Neuroscience: Alzheimer's disease. Nature 2009; 461: 895-7.

[133] Huijbregts PP, Feskens EJ, Rasanen L, et al. Dietary patterns and cognitive function in elderly men in finland, italy and the netherlands. Eur J Clin Nutr 1998; 52: 826-31.

[134] Correa Leite ML, Nicolosi A, Cristina S, Hauser WA, Nappi G. Nutrition and cognitive deficit in the elderly: A population study. Eur J Clin Nutr 2001; 55: 1053-8.

[135] Shatenstein B, Ferland G, Belleville S, et al. Diet quality and cognition among older adults from the nuage study. Exp Gerontol 2012; 47: 353-60.

[136] Tangney CC, Kwasny MJ, Li H, Wilson RS, Evans DA, Morris MC. Adherence to a mediterranean-type dietary pattern and cognitive decline in a community population. Am J Clin Nutr 2011; 93: 601-7.

[137] Wengreen HJ, Neilson C, Munger R, Corcoran C. Diet quality is associated with better cognitive test performance among aging men and women. J Nutr 2009; 139: 1944-9.

[138] Bach-Faig A, Berry EM, Lairon D, et al. Mediterranean diet pyramid today. Science and cultural updates. Public Health Nutr 2011; 14: 2274-84.

[139] Trichopoulou A, Costacou T, Bamia C, Trichopoulos D. Adherence to a mediterranean diet and survival in a greek population. $\mathrm{N}$ Engl $\mathrm{J}$ Med 2003; 348: 2599-608.

[140] Estruch R, Ros E, Salas-Salvado J, et al. Primary prevention of cardiovascular disease with a mediterranean diet. N Engl J Med 2013; 368: 1279-90.

[141] Valls-Pedret C, Sala-Vila A, Serra-Mir M, et al. Mediterranean diet and age-related cognitive decline: A randomized clinical trial. JAMA Intern Med 2015; 175: 1094-103.

[142] Martinez-Lapiscina EH, Clavero P, Toledo E, et al. Mediterranean diet improves cognition: The predimed-navarra randomised trial. J Neurol Neurosurg Psychiatry 2013; 84: 1318-25.

[143] Scarmeas N, Stern Y, Tang MX, Mayeux R, Luchsinger JA. Mediterranean diet and risk for alzheimer's disease. Ann Neurol 2006; 59: 912-21

[144] Scarmeas N, Luchsinger JA, Mayeux R, Stern Y. Mediterranean diet and alzheimer disease mortality. Neurology 2007; 69: 1084-93.

[145] Scarmeas N, Stern Y, Mayeux R, Manly JJ, Schupf N, Luchsinger JA. Mediterranean diet and mild cognitive impairment. Arch Neurol 2009; 66: 216-25.

[146] Scarmeas N, Luchsinger JA, Schupf N, et al. Physical activity, diet, and risk of alzheimer disease. JAMA 2009; 302: 627-37.

[147] Gu Y, Luchsinger JA, Stern Y, Scarmeas N. Mediterranean diet, inflammatory and metabolic biomarkers, and risk of alzheimer's disease. J Alzheimers Dis 2010; 22: 483-92.

[148] Feart C, Samieri C, Rondeau V, et al. Adherence to a mediterranean diet, cognitive decline, and risk of dementia. JAMA 2009; 302: 638-48.

[149] Feart C, Torres MJ, Samieri C, et al. Adherence to a mediterranean diet and plasma fatty acids: Data from the bordeaux sample of the three-city study. Br J Nutr 2011; 106: 149-58

[150] Solfrizzi V, Panza F, Frisardi V, et al. Diet and alzheimer's disease risk factors or prevention: The current evidence. Expert Rev Neurother 2011; 11: 677-708.
[151] Cherbuin N, Anstey KJ. The mediterranean diet is not related to cognitive change in a large prospective investigation: The path through life study. Am J Geriatr Psychiatry 2012; 20: 635-9.

[152] Gardener S, Gu Y, Rainey-Smith SR, et al.Adherence to a mediterranean diet and alzheimer's disease risk in an australian population. Transl Psychiatry 2012; 2: e164.

[153] Yannakoulia M, Kontogianni M, Scarmeas N. Cognitive health and mediterranean diet: Just diet or lifestyle pattern? Ageing Res Rev 2015; 20: 74-8.

[154] Miyagi S, Iwama N, Kawabata T, Hasegawa K. Longevity and diet in okinawa, japan: The past, present and future. Asia Pac J Public Health 2003; 15 Suppl: S3-9.

[155] Willcox DC, Willcox BJ, Todoriki H, Suzuki M. The okinawan diet: Health implications of a low-calorie, nutrient-dense, antioxidant-rich dietary pattern low in glycemic load. J Am Coll Nutr 2009; 28 Suppl: S500-16.

[156] Willcox BJ, Willcox DC, Todoriki H, et al. Caloric restriction, the traditional okinawan diet, and healthy aging: The diet of the world's longest-lived people and its potential impact on morbidity and life span. Ann N Y Acad Sci 2007; 1114: 434-55.

[157] Yamada T, Kadekaru H, Matsumoto S, et al. Prevalence of dementia in the older japanese-brazilian population. Psychiatry Clin Neurosci 2002; 56: 71-5.

[158] Dodge HH, Katsumata Y, Todoriki H, et al. Comparisons of plasma/serum micronutrients between okinawan and oregonian elders: A pilot study. J Gerontol A Biol Sci Med Sci 2010; 65: 1060-7.

[159] Ramesh BN, Rao TS, Prakasam A, Sambamurti K, Rao KS Neuronutrition and alzheimer's disease. J Alzheimers Dis 2010; 19: 1123-39.

[160] Shatenstein B, Kergoat MJ, Reid I. Poor nutrient intakes during 1year follow-up with community-dwelling older adults with earlystage alzheimer dementia compared to cognitively intact matched controls. J Am Diet Assoc 2007; 107: 2091-9.

[161] Siervo M, Arnold R, Wells JC, et al. Intentional weight loss in overweight and obese individuals and cognitive function: A systematic review and meta-analysis. Obes Rev 2011; 12: 968-83.

[162] Siervo M, Nasti G, Stephan BC, et al. Effects of intentional weight loss on physical and cognitive function in middle-aged and older obese participants: A pilot study. J Am Coll Nutr 2012; 31: 79-86.

[163] Carter CS, Leeuwenburgh C, Daniels M, Foster TC. Influence of calorie restriction on measures of age-related cognitive decline: Role of increased physical activity. J Gerontol A Biol Sci Med Sci 2009; 64: 850-9.

[164] Levine B, Packer M, Codogno P. Development of autophagy inducers in clinical medicine. J Clin Invest 2015; 125: 14-24.

[165] Giem P, Beeson WL, Fraser GE. The incidence of dementia and intake of animal products: Preliminary findings from the adventist health study. Neuroepidemiology 1993; 12: 28-36.

[166] Hallbook T, Ji S, Maudsley S, Martin B. The effects of the ketogenic diet on behavior and cognition. Epilepsy Res 2012; 100: 304-9.

[167] Balietti M, Casoli T, Di Stefano G, Giorgetti B, Aicardi G, Fattoretti P. Ketogenic diets: An historical antiepileptic therapy with promising potentialities for the aging brain. Ageing Res Rev 2010; 9: 273-9

[168] Reger MA, Henderson ST, Hale C, et al. Effects of betahydroxybutyrate on cognition in memory-impaired adults Neurobiol Aging 2004; 25: 311-4.

[169] Henderson ST, Vogel JL, Barr LJ, Garvin F, Jones JJ, Costantini LC. Study of the ketogenic agent ac-1202 in mild to moderate alzheimer's disease: A randomized, double-blind, placebocontrolled, multicenter trial. Nutr Metab (Lond) 2009; 6: 31 .

[170] Stafstrom CE, Rho JM. The ketogenic diet as a treatment paradigm for diverse neurological disorders. Front Pharmacol 2012; 3: 59.

[171] Fuehrlein BS, Rutenberg MS, Silver JN, et al. Differential metabolic effects of saturated versus polyunsaturated fats in ketogenic diets. J Clin Endocrinol Metab 2004; 89: 1641-5.

[172] Brewer GJ. The risks of free copper in the body and the development of useful anticopper drugs. Curr Opin Clin Nutr Metab Care 2008; 11: 727-32.

[173] Morris MC, Evans DA, Tangney CC, et al. Dietary copper and high saturated and trans fat intakes associated with cognitive decline. Arch Neurol 2006; 63: 1085-8.

[174] Pajonk FG, Kessler H, Supprian T, et al. Cognitive decline correlates with low plasma concentrations of copper in patients 
with mild to moderate alzheimer's disease. J Alzheimers Dis 2005; 8: 23-7.

[175] Squitti R, Siotto M, Polimanti R. Low-copper diet as a preventive strategy for alzheimer's disease. Neurobiol Aging 2014; 35 Suppl 2: $\mathrm{S} 40-50$

[176] Loef M, Walach H. Copper and iron in alzheimer's disease: A systematic review and its dietary implications. Br J Nutr 2012; 107: 7-19.

[177] Tyson CC, Nwankwo C, Lin PH, Svetkey LP. The dietary approaches to stop hypertension (dash) eating pattern in special populations. Curr Hypertens Rep 2012; 14: 388-96.

[178] Wengreen H, Munger RG, Cutler A, et al. Prospective study of dietary approaches to stop hypertension- and mediterranean-style dietary patterns and age-related cognitive change: The cache county study on memory, health and aging. Am J Clin Nutr 2013; 98: 1263-71.

[179] Morris MC, Tangney CC, Wang Y, et al. Mind diet slows cognitive decline with aging. Alzheimers Dement 2015; 11: 1015-22.

[180] Morris MC, Tangney CC, Wang Y, Sacks FM, Bennett DA, Aggarwal NT. Mind diet associated with reduced incidence of alzheimer's disease. Alzheimers Dement 2015; 11: 1007-14.

[181] Manheimer EW, van Zuuren EJ, Fedorowicz Z, Pijl H. Paleolithic nutrition for metabolic syndrome: Systematic review and metaanalysis. Am J Clin Nutr 2015 Aug 12 [Epub ahead of print].

[182] Boraxbekk CJ, Stomby A, Ryberg M, et al. Diet-induced weight loss alters functional brain responses during an episodic memory task. Obes Facts 2015; 8: 261-72.

[183] Utermann G. Alzheimer's disease. The apolipoprotein e connection. Curr Biol 1994; 4: 362-5. 